\title{
ORIGINAL
}

ARTICLES

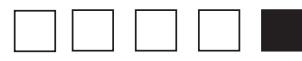

\section{Point-of-Care Ultrasound in Family Medicine Residencies 5-Year Update: A CERA Study}

Jeffrey W.W. Hall, MD; Harland Holman, MD; Tyler Barreto, MD, MPH; Paul Bornemann, MD; Andrew Vaughan, MD; Kevin J. Bennett, PhD; Jeffery Chamberlain, MD; Taft Micks, MD; Douglas M. Maurer, DO, MPH; George R. Bergus, MD, MA

BACKGROUND AND OBJECTIVES: In 2014, family medicine residency programs began to integrate point-of-care ultrasound (POCUS) into training, although very few had an established POCUS curriculum. This study aimed to evaluate the resources, barriers, and scope of POCUS training in family medicine residencies 5 years after its inception.

METHODS: Questions regarding current training and use of POCUS were included in the 2019 Council of Academic Family Medicine Educational Research Alliance (CERA) survey of family medicine residency program directors, and results compared to similar questions on the 2014 CERA survey.

RESULTS: POCUS is becoming a core component of family medicine training programs, with $53 \%$ of program directors reporting establishing or an established core curriculum. Only $11 \%$ of program directors have no current plans to add POCUS training to their program, compared to $41 \%$ in 2014 . Despite this increase in training, the reported clinical use of POCUS remains uncommon. Only $27 \%$ of programs use six of the eight surveyed POCUS modalities more than once per year. The top three barriers to including POCUS in residency training in 2019 have not changed since 2014, and are (1) a lack of trained faculty, (2) limited access to equipment, and (3) discomfort with interpreting images without radiologist review.

CONCLUSIONS: Training in POCUS has increased in family medicine residencies over the last 5 years, although practical use of this technology in the clinical setting may be lagging behind. Further research should explore how POCUS can improve outcomes and reduce costs in the primary care setting to better inform training for this technology.

(Fam Med. 2020;52(7):505-11.)

doi: 10.22454/FamMed.2020.223648

$\mathbf{P}$ oint-of-care ultrasound (POCUS) refers to clinician-performed, bedside ultrasound examinations that follow defined protocols to answer specific clinical questions. Applications for POCUS are wide ranging and can be used across multiple medical specialties, status. ${ }^{8-11}$ With growing evidence for POCUS in primary care, many educational institutions including family medicine residency programs have integrated ultrasound education into their curricula. ${ }^{12}$

Questions included in the 2014 Council of Academic Family Medicine Educational Research Alliance (CERA) survey of family medicine residency program directors sought to investigate the status of POCUS training in family medicine residency programs. At the time, data suggested that only $2.2 \%$ of family medicine residencies had an established curriculum, but $29 \%$ of respondents indicated that they had started a program within the past year and $11.2 \%$ were in the process of developing a POCUS curriculum. ${ }^{13}$

POCUS training continues to develop and formalize. Professional

From the Department of Family and Preventive Medicine, University of South Carolina School of Medicine (Drs Hall, Bornemann, Vaughan, and Bennett); Spectrum Health/Michigan State University College of Human Medicine (Dr Holman); Sea Mar Marysville Family Medicine Residency (Dr Barreto); Mercy Health Department of Family Medicine, Michigan State University College of Human Medicine (Dr Chamberlain); Brandon Regional Health Centre, Department of Emergency Medicine, University of Manitoba (Dr Micks); Army Medical Education Directorate, Office of the Surgeon General (Dr Maurer); and the Departments of Family Medicine and Physician Assistant Studies, University of Iowa Carver College of Medicine (Dr Bergus). 
organizations such as the American Academy of Family Physicians now encourage every family medicine residency program to include POCUS training, ${ }^{14}$ and have developed curriculum guidelines for family medicine residents. ${ }^{15}$ Medical school POCUS curriculum integration continues to grow with more than 180 medical schools around the world reporting POCUS curriculum to the American Institute of Ultrasound in Medicine, compared to approximately 20 in $2014 .{ }^{16}$ Data also suggest that medical students with ultrasound training in school consider ultrasound training opportunities when selecting a residency program. ${ }^{17}$

It is not currently known how these recent advancements in research and curriculum development have affected POCUS training across family medicine residency programs. Through a follow-up CERA survey, we sought to explore the updated status of POCUS training in family medicine by examining how ultrasound is being utilized across family medicine residencies, and understand potential barriers to POCUS use in the specialty.

\section{Methods}

We developed a series of questions building on a previous survey completed in 2014. ${ }^{13}$ The previous study investigated program directors' perceptions of likely future use of POCUS, along with curricula, attitudes, and barriers to implementation. This new inquiry investigates the family medicine program directors' perceptions of current use of POCUS, as well as revisiting curricula and barriers to training regarding POCUS in family medicine residency programs. We left questions regarding curricula and barriers largely unchanged to allow direct comparisons between years. We modified questions regarding current use of POCUS to better investigate current use in 2019 , rather than ask directors to estimate likelihood of future use (2014). By consensus among the authors, we determined seven of the most common uses of POCUS in 2014. One additional modality (lung ultrasound) was added to the 2019 survey.

This set of questions was included as part of a larger omnibus survey conducted by the Council of Academic Family Medicine Educational Research Alliance (CERA). The methodology of the CERA Program Director Survey has previously been described in detail. ${ }^{18}$ The CERA Steering Committee evaluated questions for consistency with the overall subproject aim, readability, and existing evidence of reliability and validity. Family medicine educators who were not part of the target population pretested the survey. Questions were modified following pretesting for flow, timing, and readability. The American Academy of Family Physicians Institutional Review Board approved the project in May 2019. Data were collected from May 2019 to July 2019.

The sampling frame for the survey was all Accreditation Council for Graduate Medical Education-accredited US family medicine residency program directors as identified by the Association of Family Medicine Residency Directors. Email invitations to participate were delivered with the survey utilizing the online program Survey Monkey. Seven follow-up emails to encourage nonrespondents to participate were sent after the initial email invitation.

\section{Analysis}

This analysis compares the results of similar CERA surveys distributed in 2014 and 2019. Survey responses were aggregated and coded using SAS 9.4. Differences in these proportions between the two survey years were estimated using Wald $c^{2}$ analysis with an $\alpha$ of 0.05 . For perceived barriers, respondents were able to rank their top three responses. The first ranked response received a score of 3 , the scored ranked response received a rank of 2 , and the third ranked response received a score of 1 . We then summed these weighted scores and sorted them from highest to lowest, with the highest scores indicating those responses more commonly cited and ranked highly by the respondents, with the differences in the relative ranks from the previous survey noted.

\section{Results}

The 2019 CERA Program Directors 2019 received responses from 261 out of 616 surveys sent for an overall response rate of $42.4 \%$. While this includes a higher total number of responses, it is a small percentage reduction from the 2014 survey's response rate of $50 \%$.

\section{Current Prevalence of Practice and Curricula}

POCUS training in family medicine residency programs has generally expanded and matured between 2014 and 2019, albeit with some notable challenges. The results of overall POCUS training are summarized in Table 1. POCUS is increasingly a core part of family medicine training, with percentage of programs "in the process of establishing a core POCUS curriculum" tripling from $12 \%$ in 2014 to $38 \%$ in $2019(P<.05)$. The percentage of respondents reporting an established curriculum also tripled from $2 \%$ in 2014 to $6 \%$ in 2019 $(P<.001)$. On the other end of the scale, the percentage of programs that "had no plans to establish POCUS training" dropped significantly from $41 \%$ in 2014 to $11 \%$ in 2019 $(P<.0001)$. In a subgroup analysis, programs with fewer than 31 residents were more likely to have no plans to establish POCUS training $(P<.05)$, as were community-based programs, $(P<.05)$. Table 2 reports the responses relating to curricular components of POCUS training. Notably, all curricular components increased significantly over the 5-year period. The 2019 survey specified which type of faculty provided supervision of POCUS images, and found family medicine residents have their ultrasound images reviewed more commonly by family medicine faculty 
Table 1: Program Directors' Descriptions of Point-of-Care Ultrasound Education in Their Residencies

\begin{tabular}{|c|c|c|}
\hline Which best describes the current status of POCUS (beyond OB ultrasound) at your residency? & $\begin{array}{c}2014 \\
\mathrm{~N}=224, \mathrm{n}(\%)\end{array}$ & $\begin{array}{c}2019 \\
\mathrm{~N}=261, \mathrm{n}(\%)\end{array}$ \\
\hline We have no plans to establish ultrasound training. & $89(41)$ & $27(11)$ \\
\hline We are considering the addition of ultrasound training to our program. & $25(12)$ & $56(22)$ \\
\hline We have elective opportunities in point of care ultrasound for our residents. & $6(3)$ & $35(14)$ \\
\hline We are in the process of establishing a core ultrasound curriculum or training. & $25(12)$ & $95(38)$ \\
\hline We have recently (last year) established a core ultrasound curriculum or training. & $65(30)$ & $23(9)$ \\
\hline We have an established core ultrasound curriculum or training. & $5(2)$ & $15(6)$ \\
\hline
\end{tabular}

Difference between 2014 and 2019 significantly different $(P<.05)$.

Table 2: Program Directors' Report of Point-of-Care Ultrasound Training Methods in Their Residencies

\begin{tabular}{|c|c|c|c|}
\hline $\begin{array}{l}\text { In what ways does your family medicine residency program } \\
\text { include training in POCUS? (Mark all that apply) }\end{array}$ & $\begin{array}{c}2014 \\
N=224\end{array}$ & $\begin{array}{c}2019 \\
\mathrm{~N}=261\end{array}$ & $\begin{array}{c}P \text { Value, } \\
2014 \text { vs } \\
2019\end{array}$ \\
\hline Shadowing or observing clinicians or technicians that perform ultrasound & $52 \%$ & $69 \%$ & .0002 \\
\hline Review of ultrasound images in didactic conferences & $15 \%$ & $40 \%$ & $<.001$ \\
\hline Residents have supervised hands-on experiences with ultrasound equipment & $40 \%$ & $64 \%$ & $<.001$ \\
\hline Residents submit a log of completed ultrasound examinations & $9 \%$ & $20 \%$ & .0008 \\
\hline Resident-performed ultrasound examinations are reviewed by faculty & $16 \%$ & & \\
\hline $\begin{array}{l}\text { Resident-performed ultrasound examinations are reviewed by family medicine } \\
\text { faculty }\end{array}$ & & $26 \%$ & \\
\hline Resident-performed ultrasound examinations are reviewed by radiology faculty & & $5 \%$ & \\
\hline $\begin{array}{l}\text { Resident-performed ultrasound examinations are reviewed by emergency room } \\
\text { faculty (not asked in 2014) }\end{array}$ & & $18 \%$ & \\
\hline
\end{tabular}

than faculty in departments of radiology or emergency medicine.

\section{Current Perceptions of Use}

The 2014 survey took seven different modalities of POCUS and asked program directors to estimate the likelihood of use, "in their graduates' future practices." The 2019 study asked program directors to estimate the frequency of use of these modalities "in their current practice," so the results are not directly comparable between years. Table 3 summarizes the 2019 results of program directors responding that physicians in their programs currently use these modalities either once per week, once per month, or once per year. While all modalities are used at least occasionally by some programs, most programs report infrequent use. In fact, six of the eight modalities we surveyed were rated as never used by over $73 \%$ of program directors.

\section{Perceived Barriers}

The three most significant barriers to pursuing training did not change in order between 2014 and 2019, and remain a lack of trained faculty, limited access to equipment, and discomfort with interpreting images without radiologist review (Table 4). The second-tier obstacles did change in rank. Notably, financial issues such as time required to perform the exam during a busy clinic and insurance reimbursements were reported more frequently as problems, while restrictive hospital policies and inadequate learner interest were listed less often.

\section{Graduate Competency}

While the other questions focussed on the training program as a whole, program directors were also asked about the percentage of graduates from their program over the past 3 years who are competent to perform POCUS. The results are shown in Figure 1. Only 10 program directors out of 261 responding reported that over half of their graduates are competent to use point-of-care ultrasound in a clinical setting.

\section{Discussion}

POCUS training has substantially expanded in family medicine residencies over the last 5 years, but it still faces significant barriers to clinical implementation. Nearly twothirds of programs now report either having core curricula or elective 
Table 3: Program Directors' Reporting Point-of-Care Ultrasound Clinical Use in Their Residencies in 2019

\begin{tabular}{|c|c|c|c|c|}
\hline \multirow{2}{*}{$\begin{array}{l}\text { How often are physicians in your program currently using the following POCUS } \\
\text { applications in their training and practice? } \\
\qquad N=248\end{array}$} & \multicolumn{2}{|c|}{$\begin{array}{l}\text { Once per Year } \\
\text { or More }\end{array}$} & \multicolumn{2}{|c|}{$\begin{array}{l}\text { Less Than Once } \\
\text { per Year or Never }\end{array}$} \\
\hline & $\mathbf{n}$ & $\%$ & $\mathbf{n}$ & $\%$ \\
\hline $\begin{array}{l}\text { Procedural guidance (eg, joint injection, paracentesis, central venous line } \\
\text { placement) }\end{array}$ & 173 & 69 & 76 & 31 \\
\hline Musculoskeletal ultrasound evaluation for tendinopathy & 117 & 47 & 132 & 53 \\
\hline Right upper-quadrant abdominal ultrasound for evaluating biliary colic & 64 & 26 & 185 & 74 \\
\hline $\begin{array}{l}\text { Limited diagnostic evaluation in trauma: (ie, focused assessment with } \\
\text { sonography for trauma) }\end{array}$ & 66 & 27 & 182 & 73 \\
\hline Lower extremity doppler for evaluation of deep venous thrombosis & 57 & 23 & 191 & 77 \\
\hline Screening examinations for abdominal aortic aneurysm & 46 & 19 & 202 & 81 \\
\hline $\begin{array}{l}\text { Limited echocardiogram (eg, left ventricular hypertrophy screening, ejection } \\
\text { fraction determination) }\end{array}$ & 47 & 19 & 202 & 81 \\
\hline Lung ultrasound for evaluation of dyspnea & 47 & 19 & 200 & 81 \\
\hline
\end{tabular}

opportunities in POCUS. Of the remaining $31 \%$ who have not yet begun establishing POCUS as part of their curriculum, two-thirds of them are considering adding it. Additionally, training experiences have become more formalized, with inclusion of ultrasound images during didactic sessions, faculty review of ultrasound images, and use of required ultrasound logs roughly doubling over this period.

While training in POCUS continues to grow, the current clinical use of POCUS modalities remains comparatively low in residencies. Only 10 of 261 program directors believe that a majority of their graduates are competent to use POCUS. Of eight possible POCUS modalities, procedural guidance is the only one that a majority of program directors report physicians in their practice use at least annually. Conversely, at least $75 \%$ of directors report their physicians in their practice use 6 of the 8 modalities less than once a year.

The surveyed barriers to inclusion of POCUS training into residency programs explains some of the discrepancy between training and actual use. These barriers appear to be significant impediments: in 2014 a total of $40 \%$ of respondents indicated they were in the process of establishing training, or had done so within the last year. Based on this response, we would have expected at least $40 \%$ of responders having an established curriculum in 2019. However, in 2019 only $6 \%$ of programs reported an established curriculum, suggesting that implementing a truly effective curriculum turned out to be more challenging than was expected in 2014. It is also possible that since criteria for POCUS curricula have been more formally described and widely circulated ${ }^{15}$ some program directors may have felt their existing curricula did not meet the bar of being "established."

The discrepancy between the growth of POCUS training and limited growth in clinical use suggests there are barriers not only to implementing POCUS training, but also barriers to incorporating this new technology into clinical primary care. Many uses of POCUS were developed for the acute care setting such as emergency rooms or hospital settings, and may not be as appropriate for ambulatory settings. Ambulatory settings have somewhat different patient characteristics, emphases, and billing processes that affect the utility of this new technology. For example, family physicians working in a rural emergency department (ED) will find POCUS an invaluable tool for evaluating a patient with right upper-quadrant pain. In such cases, POCUS would likely clarify the diagnosis more quickly than calling in a sonography technician after hours. When these clinicians compare the alternatives of POCUS versus a formal radiology ultrasound, POCUS will more likely improve patient flow through the ED and improve the efficiency of care. In contrast, family physicians in an ambulatory clinic evaluating patients with right upperquadrant pain will probably find POCUS to be more time consuming and less efficient than the alternative of ordering an outpatient ultrasound. Such ambulatory clinicians would rightly want to know how the time spent performing POCUS would be reimbursed and whether or not this new process would improve the patient's outcome.

While the top three barriers to POCUS training did not change since 2014, our surveyed barriers in the second tier reported increased concerns regarding financial reimbursements, clinic efficiency, and demonstration of improved patient outcomes. Perhaps the top three barriers persist because uncertain financial incentives and inadequately proven patient outcomes prevent faculty from investing time in learning POCUS, and prevent clinics from investing money in purchasing equipment.

If financial and outcome concerns are the barriers behind the barriers, studies demonstrating improved outcomes or cost savings for 
Table 4: Program Directors' Ranking Perceived Barriers to Point-of-Care Ultrasound in Their Residencies

\begin{tabular}{|c|c|c|c|c|}
\hline \multicolumn{2}{|l|}{2014} & \multirow[b]{2}{*}{$\begin{array}{l}\text { Change in } \\
\text { Rank }\end{array}$} & \multicolumn{2}{|r|}{2019} \\
\hline $\begin{array}{l}\text { Barriers that have deterred or made it } \\
\text { difficult for the establishment of point- } \\
\text { of-care ultrasound training in your } \\
\text { residency program include (rank sum): }\end{array}$ & Rank & & Rank & $\begin{array}{l}\text { Barriers that have deterred or made it } \\
\text { difficult for the establishment of point- } \\
\text { of-care ultrasound training in your } \\
\text { residency program include (rank sum): }\end{array}$ \\
\hline $\begin{array}{l}\text { My faculty lacks appropriate training in } \\
\text { performing point-of-care ultrasound. (487) }\end{array}$ & 1 & & 1 & $\begin{array}{l}\text { My faculty lacks appropriate training in } \\
\text { performing point-of-care ultrasound. (580) }\end{array}$ \\
\hline $\begin{array}{l}\text { Our program does not have adequate access } \\
\text { to ultrasound equipment. (212) }\end{array}$ & 2 & & 2 & $\begin{array}{l}\text { Our program does not have adequate } \\
\text { access to ultrasound equipment. }(219)\end{array}$ \\
\hline $\begin{array}{l}\text { Physicians feel uncomfortable interpreting } \\
\text { ultrasound images without having a } \\
\text { radiologist available to over-read them. (113) }\end{array}$ & 3 & & 3 & $\begin{array}{l}\text { Physicians feel uncomfortable } \\
\text { interpreting ultrasound images without } \\
\text { having a radiologist available to over-read } \\
\text { them. (157) }\end{array}$ \\
\hline $\begin{array}{l}\text { Clinic or hospital system policies do not } \\
\text { permit family physicians to use ultrasound } \\
\text { in a meaningful way. }(96)\end{array}$ & 4 & & 4 & $\begin{array}{l}\text { The time physicians spend performing } \\
\text { ultrasound examinations may not be } \\
\text { reimbursed by insurance. (99) }\end{array}$ \\
\hline $\begin{array}{l}\text { The time physicians spend performing } \\
\text { ultrasound examinations may not be } \\
\text { reimbursed by insurance. }(90)\end{array}$ & 5 & & 5 & $\begin{array}{l}\text { Ultrasound examinations are too time } \\
\text { consuming to be done in a busy clinic. } \\
\text { (98) }\end{array}$ \\
\hline $\begin{array}{l}\text { There is no time in our current curriculum } \\
\text { to add ultrasound training. ( } 86 \text { ) }\end{array}$ & 6 & & 6 & $\begin{array}{l}\text { Clinic or hospital system policies do } \\
\text { not permit Family Physicians to use } \\
\text { ultrasound in a meaningful way. (85) }\end{array}$ \\
\hline $\begin{array}{l}\text { Our program does not see a need for family } \\
\text { doctors trained in point-of-care ultrasound. } \\
(44)\end{array}$ & 7 & & 7 & $\begin{array}{l}\text { There is no time in our current } \\
\text { curriculum to add ultrasound training. } \\
\text { (82) }\end{array}$ \\
\hline $\begin{array}{l}\text { Ultrasound examinations are too time- } \\
\text { consuming to be done in a busy clinic. }(36)\end{array}$ & 8 & & 8 & $\begin{array}{l}\text { There are insufficient data to prove that } \\
\text { point-of-care-ultrasound improves patient } \\
\text { outcomes in the ambulatory setting. (39) }\end{array}$ \\
\hline $\begin{array}{l}\text { There are insufficient data to prove that } \\
\text { point-of-care-ultrasound improves patient } \\
\text { outcomes in the ambulatory setting. (34) }\end{array}$ & 9 & & 9 & $\begin{array}{l}\text { Our program does not see a need for } \\
\text { family doctors trained in point-of-care } \\
\text { ultrasound. (23) }\end{array}$ \\
\hline $\begin{array}{l}\text { Students and residents are uninterested in } \\
\text { learning point of care ultrasound. (15) }\end{array}$ & 10 & & 10 & $\begin{array}{l}\text { Patients prefer ultrasounds to be done } \\
\text { by radiology departments rather than by } \\
\text { their primary physician. (13) }\end{array}$ \\
\hline $\begin{array}{l}\text { Patients prefer ultrasounds to be done by } \\
\text { radiology departments rather than by their } \\
\text { primary physician. }(0)\end{array}$ & 11 & & 11 & $\begin{array}{l}\text { Students and residents are uninterested } \\
\text { in learning point of care ultrasound. (10) }\end{array}$ \\
\hline Other & & & & Other (32) \\
\hline
\end{tabular}

POCUS in a primary care setting would be valuable toward broader implementation and training. This need for more studies of POCUS and patient-oriented outcomes was highlighted in two excellent recently published literature reviews. ${ }^{6-7}$ One of the reviews ${ }^{6}$ listed multiple POCUS uses and studies, but despite 72 curated references, could only generate one A-level recommendation for POCUS use using the Strength of Recommendation Taxonomy. ${ }^{19}$
Financial impact studies are also sorely needed. The other review ${ }^{7}$ referenced three articles that found lower health costs with primary care ultrasound, although the economic reviews were reportedly limited and the referenced articles were published in 2002 or earlier.

Financial barriers to individual physicians and clinics stem from uncertainties in reimbursements for POCUS. Not all insurers recognize POCUS as a reimbursable service.
Those that do require documentation of medical necessity, permanent storage of images, and a written report. ${ }^{20}$ Clarifying and simplifying billing regulations and practices will be important to widely implement POCUS in an ambulatory setting. Technological upgrades are likely to increase POCUS ease of use through improved portability, shortened boot-up times, enhanced image clarity, and simplified image transfer to the electronic medical records. 
Figure 1: Program Directors' Assessment of Point-of-Care Ultrasound Competency Upon Residency Graduation in 2019

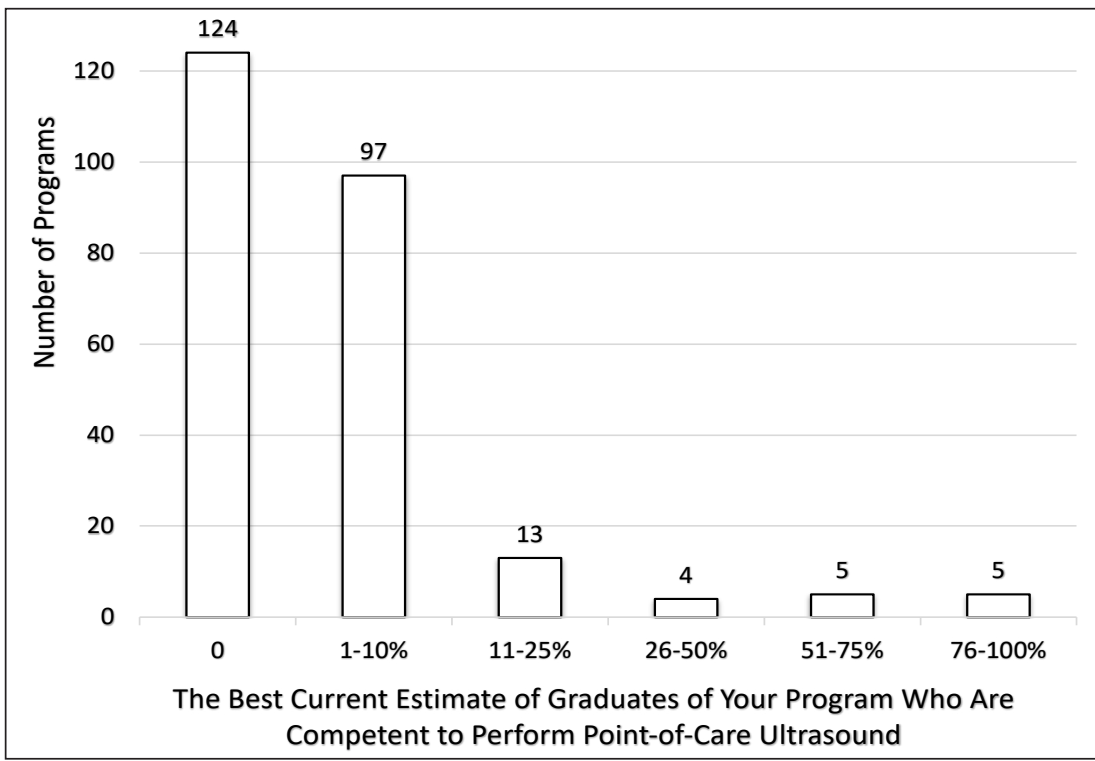

These advancements may accelerate POCUS uptake by clinicians.

As patient-oriented evidence increases and financial barriers are addressed, an increasing number of faculty and residents will likely become proficient at using POCUS in multiple settings. Family physicians have a broad level of training and often perform a wide variety of procedures, however often any single procedure may be uncommon. Maintaining skills in ultrasound for infrequently used modalities is another question that will need to be addressed over time. Studies providing insight on effectively maintaining and improving skills over time will become important.

Interest in POCUS is unlikely to disappear. Ultrasound devices are becoming more affordable, more portable, and are beginning to incorporate more user-friendly technology including artificial intelligence. In addition, this growing interest in POCUS is not limited to family medicine residencies in the United States. As of 2018, 71\% of Canadian family medicine residency programs were either currently offering POCUS training or were planning to introduce it to their programs. The
Canadian residency directors also identified several of the same barriers reported by US family medicine residency directors. Over half $(57 \%)$ of the Canadian program directors identified a lack of adequate equipment, lack of instructors, and lack of available time in the curriculum. ${ }^{21}$ It is notable that despite very different health care systems in the United States and Canada, residency directors in both countries report growing interest in POCUS and are hampered by some of the same barriers.

The promise of POCUS is not to convert primary care clinicians into full-time sonographers, but to enable primary care clinicians to use this new technology as proficiently as they currently use their stethoscopes. The question, "Can family physicians be trained to perform POCUS?" has been answered affirmatively by multiple studies, and likely drives our survey's documented growth in POCUS training during residency. The question, "How should family physicians ideally use POCUS," is not as well resolved, and may explain the more limited clinical use reported here. We need further investigations on how POCUS can improve patients' outcomes in primary care settings, and we need analyses of the positive or negative impacts of POCUS on health care costs. These investigations will help clarify the best uses for POCUS and provide the incentives needed to more widely adopt this technology.

FINANCIAL SUPPORT: The 2019 Council of Academic Family Medicine Educational Research Alliance (CERA) Survey provided inkind support for the survey.

CORRESPONDING AUTHOR: Address correspondence to Dr Jeffrey W.W. Hall, Department of Family and Preventive Medicine, University of South Carolina School of Medicine, 3209 Colonial Drive, Columbia, SC 29212. 803-434-6152. Fax: 803-434-8374. Jeff.hall@ uscmed.sc.edu.

\section{References}

1. Kendall JL, Hoffenberg SR, Smith RS. History of emergency and critical care ultrasound: the evolution of a new imaging paradigm. Crit Care Med. 2007; 35:5 S126 - S130

2. Beaulieu Y, Marik PE. Bedside ultrasonography in the ICU: part 1. Chest. 2005;128(2):881895

3. Levy JA, Noble VE. Bedside ultrasound in pediatric emergency medicine. Pediatrics. 2008;121(5):e1404-e1412.

4. Kobal SL, Atar S, Siegel RJ. Hand-carried ultrasound improves the bedside cardiovascular examination. Chest. 2004;126(3):693-701.

5. Russell TC, Crawford PF. Ultrasound in the austere environment: a review of the history, indications, and specifications. Mil Med. 2013;178(1):21-28

6. Arnold MJ, Jonas CE, Carter RE. Point-ofcare ultrasonography. Am Fam Physician. 2020;101(5):275-285.

7. Andersen CA, Holden S, Vela J, Rathleff MS, Jensen MB. Point-of-care ultrasound in general practice: a systematic review. Ann Fam Med. 2019;17(1):61-69.

8. Mjølstad OC, Snare SR, Folkvord L, et al. Assessment of left ventricular function by GPs using pocket-sized ultrasound. Fam Pract. 2012;29(5):534-540.

9. Brennan JM, Ronan A, Goonewardena S, et al. Handcarried ultrasound measurement of the inferior vena cava for assessment of intravascular volume status in the outpatient hemodialysis clinic. Clin J Am Soc Nephrol. 2006;1(4):749-753.

10. Blois B. Office-based ultrasound screening for abdominal aortic aneurysm. Can Fam Physician. 2012;58(3):e172-e178.

11. Spencer KT, Kimura BJ, Korcarz CE, Pellikka PA, Rahko PS, Siegel RJ. Focused cardiac ultrasound: recommendations from the American Society of Echocardiography. J Am Soc Echocardiogr. 2013;26(6):567-581. 
12. Solomon SD, Saldana F. Point-of-care ultrasound in medical education-stop listening and look. N Engl J Med. 2014;370(12):1083-1085.

13. Hall JW, Holman H, Bornemann P, et al. Point of Care Ultrasound in family medicine Residency Programs: A CERA Study. Fam Med. 2015;47(9):706-711.

14. Resolution No. 602 (New York E) - Increase point of care ultrasound (POCUS). Education in Family Medicine. Leawood, KS: Congress of Delegates American Academy of Family Physicians; 2016.

15. American Academy of Family Physicians. Recommended Curriculum Guidelines for Family Medicine Residents. AAFP Reprint No. 290D. https://www.aafp.org/dam/AAFP/documents/ medical_education_residency/program_directors/Reprint290D_POCUS.pdf. Accessed June $5,2020$.
16. American Institute of Ultrasound in Medicine. AIUM Ultrasound in Medical Education Portal. http://meded.aium.org/medical-schools. Accessed March 12, 2020.

17. Neri L, Storti E, Lichtenstein D. Toward an ultrasound curriculum for critical care medicine. Crit Care Med. 2007;35(5)(suppl):S290-S304.

18. Mainous AG III, Seehusen D, Shokar N. CAFM Educational Research Alliance (CERA) 2011 residency director survey: background, methods, and respondent characteristics. Fam Med. 2012;44(10):691-693.

19. Ebell MH, Siwek J, Weiss BD, et al. Strength of recommendation taxonomy (SORT): a patient-centered approach to grading evidence in the medical literature. Am Fam Physician 2004;69(3):548-556.
20. Fujifilm Sonosite. Ultrasound reimbursement information: primary care. https://www. sonosite.com/sites/default/files/2018-SonoSitePrimary_Care-01082018.pdf. Published January, 2018. Accessed 17 March, 2020.

21. Micks T, Braganza D, Peng S, et al. Canadian national survey of point-of-care ultrasound training in family medicine residency programs. Can Fam Physician. 2018;64(10):e462e467. 